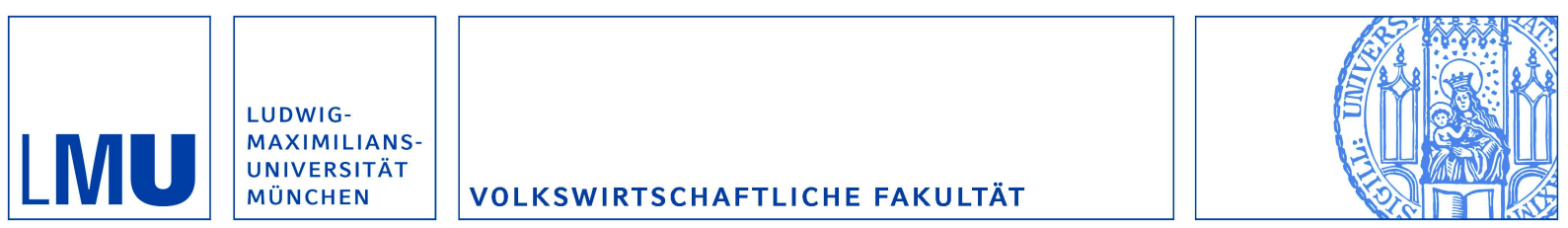

Gratz, Linda und Reisinger, Markus:

Can Naked Exclusion Be Procompetitive?

Munich Discussion Paper No. 2012-5

Department of Economics

University of Munich

Volkswirtschaftliche Fakultät

Ludwig-Maximilians-Universitäł München

Online at https://doi.org/10.5282/ubm/epub. 12733 


\title{
Can Naked Exclusion Be Procompetitive? ${ }^{\star}$
}

\author{
Linda Gratz And Markus Reisinger ${ }^{\curlyvee}$ \\ This version: August 2011
}

\begin{abstract}
Antitrust scholars have argued that exclusive contracts have anticompetitive, or at best neutral effects, if no efficiencies are generated. In contrast, this paper shows that exclusive contracts can have procompetitive effects, provided buyers are imperfect downstream competitors and contract breach is feasible. In that case an efficient entrant is not necessarily foreclosed through exclusive contracting but induces buyers to breach. Because breaching buyers have to pay expectation damages to the incumbent, the downstream profits they obtain when breaching must be large enough. Therefore, the entrant needs to set a lower wholesale price than absent exclusive contracting, leading to lower final consumer prices and higher welfare.
\end{abstract}

Keywords: Exclusive Contracting; Naked Exclusion; Contract Breach; Antitrust Policy

JEL classification: D43, K21, L12, L42

\section{Introduction}

In many recent antitrust cases incumbent upstream firms were alleged of having used exclusive contracts to deter potentially more efficient entrants, thereby harming consumers. ${ }^{1}$ In these cases courts need to balance anticompetitive effects caused by entry deterrence or increased wholesale prices against potential efficiency gains created through exclusive contracting within the vertical production chain.

\footnotetext{
We would like to thank Bernhard Ganglmair, Fabian Herweg, Klaus Schmidt, seminar participants at the Universities of Düsseldorf and Munich and participants at the IMPRS-CI Workshop 2011 for very helpful comments and suggestions.

`Linda Gratz, International Max-Planck Research School for Competition and Innovation, Hofgartenstr. 8, 80539 Munich, Germany. E-mail: linda.gratz@imprs-ci.ip.mpg.de.

Markus Reisinger, Economics Department, WHU - Otto Beisheim School of Management, Burgplatz 2, 56179 Vallendar, Germany. E-Mail: markus.reisinger@whu.edu.

${ }^{1}$ Recent examples are United States v. Transitions Optical, United States v. Dentsply, Pernod Ricard and Campbell Distillers v. Bacardi-Martini, Langnese-Iglo v. European Commission, and United States v. Microsoft.
} 
In this paper we point out that exclusive contracting can have procompetitive effects even if no efficiency gains are generated, provided downstream competition is moderate and downstream firms can breach exclusive contracts. The intuition is the following. Suppose the downstream firms signed the exclusive contract with the incumbent. In that case, the entrant may nevertheless find it profitable to enter since it can induce the downstream firm to breach the contract. Because breaching downstream firms have to pay expectation damages to the incumbent, they only breach when they can obtain sufficiently large downstream profits. Therefore, the entrant needs to sell its input at a relatively low wholesale price. Using a framework developed by Simpson and Wickelgren (2007), we show that for moderate degrees of downstream competition this mechanism leads to lower final consumer prices than without exclusive contracting and therefore to a rise in welfare.

Our result stands in stark contrast to the previous literature, which asserts that exclusive contracting has anticompetitive, or at best neutral effects, if no efficiencies are generated. As is well known, "Chicago School" scholars (e.g., Posner, 1976, and Bork, 1978) argue for a neutral effect. They assume that downstream buyers are independent monopolists (or final consumers). In this situation, where downstream firms do not compete, the incumbent's gain in profit through entry deterrence is lower than the downstream firms' loss in profit. Therefore, the incumbent is unable to compensate the downstream firms for signing exclusive contracts, given no efficiencies are generated. Rasmusen, Ramseyer and Wiley (1991) and Segal and Whinston (2000) challenge this argument, pointing out that the entrant may not be able to reach the minimum efficient scale when selling only to a fraction of buyers, implying that downstream firms exert a negative externality on each other when signing. The incumbent can induce the downstream firms to sign by exploiting this externality.

Fumagalli and Motta (2006) analyze the case in which downstream buyers are not independent monopolists but perfect Bertrand competitors and argue for a neutral effect. With perfect downstream competition the entrant needs to sell only to a single downstream firm to reach the minimum efficient scale, which removes the negative externality that signing downstream firms exert. To bring out this effect Fumagalli and Motta (2006) assume that downstream firms face a fixed fee of being active in the downstream market. When all but one firm signed the contract, the firms that signed face a higher wholesale price and therefore stay inactive, which enables the single firm that did not sign to earn monopoly profits. As a consequence, each downstream firm demands the monopoly profit as compensation for signing, so that exclusive contracting 
becomes too costly for the incumbent. Several follow-up papers show that a different picture emerges once the assumption on the fixed fee of being active is dropped. ${ }^{2}$ These papers show that it becomes easier for the incumbent to induce downstream firms to sign if downstream competition increases. ${ }^{3}$ The reason is that signing downstream firms stay active, thereby exerting competitive pressure on downstream firms that do not sign. This limits the profits that downstream firms can obtain by not signing the exclusive contract. Thus, the compensation that the incumbent needs to offer for signing decreases.

An important limitation of these papers is the assumption that once downstream firms have signed exclusive contracts, they cannot breach them later. Therefore, if all firms have signed, this inevitably leads to entry deterrence. Common law, however, provides each party to a contract the opportunity to breach by paying expectation damages to the injured party. While in some situations breach of contract may indeed be prohibitively costly due to reputational reasons or high litigation costs, it seems unreasonable to assume generally that contract breach is not feasible. Simpson and Wickelgren (2007) provide an insightful model in which they incorporate the possibility of contract breach. They analyze the cases in which downstream firms are (i) independent monopolists and (ii) (almost) perfect Bertrand competitors. The incumbent is able to induce downstream firms to sign exclusive contracts only in case (ii). Simpson and Wickelgren (2007) find, however, that due to the possibility of contract breach signing does not lead to entry deterrence. Nevertheless, exclusive contracting is anticompetitive in that case because the entrant induces just a single downstream firm to breach, and this firm monopolizes the market, leading to higher final consumer prices.

We extend the analysis of Simpson and Wickelgren (2007) to account for general degrees of product differentiation between downstream firms. Particularly moderate degrees of product differentiation are relevant and therefore important to consider as products are often physically differentiated and consumers have different preferences for one or the other good. As a central result we find that for such moderate degrees of product differentiation exclusive contracting can have procompetitive effects, even if no efficiencies are generated. To gain insight, when the degree of product differentiation is moderate, the entrant induces not just a single downstream firm but both downstream

\footnotetext{
${ }^{2}$ See, for example, Abito and Wright (2008), Wright (2008, 2009) and Kitamura (2010).

${ }^{3} \mathrm{~A}$ similar argument is put forward in earlier works by Stefanidis (1998), Yong (1999) and Simpson and Wickelgren (2001). In these papers, though, the authors assume that the incumbent can commit to a certain wholesale price when offering the exclusive contract.
} 
firms to breach because it receives sizable profits from both these firms. When breaching, the firms have to pay expectation damages to the incumbent. Thus, in order to render breaching profitable the entrant must set its wholesale price sufficiently low. In particular, the wholesale price it needs to set lies below the one that the upstream firms would set absent exclusive contracting. As a consequence, final consumer prices fall and total welfare rises. ${ }^{4}$

The paper proceeds as follows. Section 2 sets out the model. In Section 3 we present our result with a general demand function. Section 4 provides an example with a linear demand function and Section 5 concludes.

\section{The Model}

In this section we outline the model, which follows Simpson and Wickelgren (2007). Everything described below is common knowledge to all agents. We analyze an industry with an upstream and a downstream market. In the upstream market an incumbent firm $I$ and a potential entrant $E$ produce a homogeneous input good. In the downstream market two differentiated firms $i$ and $j$ process the input good at a one-to-one technology and compete in prices for final consumers.

For tractability reasons we assume that downstream firms $i$ and $j$ are symmetric. Downstream firm $i$ 's demand function when setting a price $p_{i}$ and when the rival sets a price $p_{j}$ is given by $D\left(p_{i}, p_{j} ; \gamma\right)$, with $\partial D\left(p_{i}, p_{j ;} \gamma\right) / \partial p_{i}<0, \partial D\left(p_{i}, p_{j} ; \gamma\right) / \partial p_{j} \geq 0$ and $\left|\partial D\left(p_{i}, p_{j} ; \gamma\right) / \partial p_{i}\right| \geq\left|\partial D\left(p_{i}, p_{j} ; \gamma\right) / \partial p_{j}\right|$. A downstream firm's demand is falling in its own price, it is rising in its rival's price, and the absolute effect of its own price is larger than the effect of its rival's price. In this demand function, $\gamma \in[0,1)$ is a parameter representing the degree of downstream competition or product differentiation, that is, $\partial D\left(p_{i}, p_{j ;} \gamma\right) / \partial p_{i}<0$ is weakly decreasing and $\partial D\left(p_{i}, p_{j} ; \gamma\right) / \partial p_{j} \geq 0$ is strictly increasing in $\gamma$. For $\gamma=0$, the two products are independent, implying that each downstream firm is a monopolist, that is $\partial D\left(p_{i}, p_{j} ; 0\right) / \partial p_{j}=0$ and $\left|\partial D\left(p_{i}, p_{j ;} \gamma\right) / \partial p_{i}\right|$ is minimal. As $\gamma \rightarrow 1$, the two products become perfect substitutes, implying perfect Bertrand competition, that is $\lim _{\gamma \rightarrow 1} \partial D\left(p_{i}, p_{j} ; \gamma\right) / \partial p_{j}=\infty$ and $\lim _{\gamma \rightarrow 1} \partial D\left(p_{i}, p_{j} ; \gamma\right) / \partial p_{i}=-\infty$ as long as both demands are strictly positive. We impose two technical assumptions,

\footnotetext{
${ }^{4}$ As shown by Mathewson and Winter (1987) and Bernheim and Whinston (1998) if two incumbent manufacturers compete for exclusive dealing contracts, the effects of exclusive contracting can also be procompetitive. However, the mechanisms leading to these effects - that manufacturer competition for exclusive representation is tougher than standard competition, or that exclusive dealing reduces the incentive conflict of a risk-averse retailer - are very different from the one identified in this paper, in which exclusive dealing is used for entry deterrence reasons.
} 
$\partial^{2} D\left(p_{i}, p_{j} ; \gamma\right) / \partial p_{i}^{2} \leq 0$ (or not too positive) and $\partial^{2} D\left(p_{i}, p_{j} ; \gamma\right) /\left(\partial p_{i} \partial p_{j}\right) \geq 0$, which guarantee that each downstream firm's demand function is concave and that equilibrium prices are strategic complements, i.e., $\partial p_{i} / \partial p_{j}>0$. They also ensure that firm $i$ 's profit is increasing in the cost of firm $j$.

The timing of the game is as follows (see also Table 1). In the first stage, $I$ makes simultaneous nondiscriminatory exclusive contract offers to the downstream firms. ${ }^{5}$ An exclusive contract is a compensation $x$ from $I$ to the downstream firms in exchange for the downstream firms' commitment to purchase exclusively from $I$. After observing these offers, the downstream firms simultaneously decide whether to accept or reject them. In the second stage, $E$ decides on entry. In stage 3.1, active upstream firms set wholesale prices to each available downstream firm. $I$ is able to discriminate between those downstream firms that have signed the exclusive contract (captive downstream firms) and those who have not (free downstream firms). It offers a wholesale price $w_{c}$ to captive downstream firms and a wholesale price $w_{f}$ to free downstream firms. $E$ offers a wholesale price $w_{e}$ to free downstream firms. ${ }^{6}$ Captive downstream firms can become free by breaching and paying expectation damages to $I$ in stage 3.2 . In accordance with common law I's expectation damages are based on its lost profits. It needs to be restored to the position it would have been in had the contract been performed. ${ }^{7}$ We assume, if both downstream firms breach, each one pays half of the expectation damages. In stage 3.3, $I$ and $E$ produce the input good. Free downstream firms purchase the input good from $E$ if $w_{e} \leq w_{f}$ and from $I$ if $w_{e}>w_{f}$. Captive downstream firms purchase from $I$ at $w_{c}$. Downstream firms compete for consumers by setting prices $p_{i}$ and $p_{j}$.

Table 1: TIME LiNE

\begin{tabular}{lllll}
\hline Stage 1 & Stage 2 & Stage 3.1 & Stage 3.2 & Stage 3.3 \\
\hline$I$ offers excl. contract & $E$ enters or not & $I$ sets prices $w_{f}, w_{c}$ & $i, j$ can breach & $i, j$ buy input \\
$i, j$ accept or reject & & $E$ sets price $w_{e}$ & & $i, j$ compete \\
\hline \hline
\end{tabular}

To simplify the notation, we denote the equilibrium downstream price vector $\mathbf{p}\left(w_{i}, w_{j}\right)=$ $\left[p_{i}\left(w_{i}, w_{j}\right), p_{j}\left(w_{j}, w_{i}\right)\right]^{\mathrm{T}}$ when needed as an argument in firm $i$ 's demand and $\mathbf{p}\left(w_{j}, w_{i}\right)=$

\footnotetext{
${ }^{5}$ Our results would not change if we assumed that $I$ makes sequential or discriminatory offers.

${ }^{6}$ As Simpson and Wickelgren (2007) we restrict our attention to the case of linear wholesale prices. For a brief discussion on two-part tariffs see the Conclusion.

${ }^{7}$ In accordance with Simpson and Wickelgren (2007) we consider the situation in which breaching downstream firms are subject to expectation damages. In contrast, Aghion and Bolton (1987), Innes and Sexton (1994) and Spier and Whinston (1995) assume that incumbent and downstream firms can sign contracts with liquidated damages. As will become evident later, the main mechanism driving our result would also be at work in case of liquidated damages. For a discussion on the difference between expectation and liquidated damages see Brodley and Ma (1993).
} 
$\left[p_{j}\left(w_{j}, w_{i}\right), p_{i}\left(w_{i}, w_{j}\right)\right]^{\mathrm{T}}$ when needed as an argument in firm $j$ 's demand.

Upstream firms $I$ and $E$ incur a constant marginal cost of $c_{I}$ and $c_{E}$. We assume that $E$ is more efficient than $I$, i.e., $c_{E}<c_{I}$, but that it incurs a sunk cost $f$ when entering. We further assume that $E$ is sufficiently efficient that it can cover this fixed costs when selling to both downstream firms at a wholesale price of $w_{E}^{\prime}$, where $w_{E}^{\prime}$ is the wholesale price that $E$ must charge to induce a downstream firm to breach provided the rival downstream firm does not breach. ${ }^{8}$ Therefore, we impose that $2\left(w_{E}^{\prime}-\right.$ $\left.c_{E}\right) D\left(\mathbf{p}\left(w_{E}^{\prime}, w_{E}^{\prime}\right) ; \gamma\right)>f$, where $D\left(\mathbf{p}\left(w_{E}^{\prime}, w_{E}^{\prime}\right) ; \gamma\right)$ is a downstream firm's demand given that both downstream firms face an input price of $w_{E}^{\prime}$ and set their downstream prices accordingly. ${ }^{9}$ As will become evident later, the underlying economics driving the main effect are not affected by this assumption. ${ }^{10}$

To avoid the epsilon notation on prices and compensations, we assume that the downstream firms sign the exclusive contract when they are indifferent between signing or not, they breach the exclusive contract when they are indifferent between breaching or not, and they buy from $E$ when they are indifferent between buying from $E$ or $I$.

Our equilibrium concept is subgame perfection with the additional refinement that if multiple equilibria arise, the downstream firms play the equilibrium that is Pareto dominant from their perspective. This assumption is necessary because in stage 3.2 of the game multiple equilibria can arise in which either both downstream firms or none of them breaches the exclusive contract.

Finally, we assume that $D\left(\mathbf{p}\left(c_{I}, c_{I}\right) ; \gamma\right)\left(p\left(c_{I}, c_{I}\right)-c_{I}\right) \geq D\left(\mathbf{p}\left(w_{c}, c_{I}\right) ; \gamma\right)\left(p\left(w_{c}, c_{I}\right)-c_{I}\right)$, where $w_{c}$ solves the maximization problem $\max _{w} D\left(\mathbf{p}\left(w, c_{I}\right)_{;} \gamma\right)\left(w-c_{I}\right)$. This assumption implies that a downstream firm is better off when it competes in the downstream market on the basis of its true costs $c_{I}$ than on costs $w_{c}>c_{I}$, where $w_{c}$ is set to maximize a profit function with a different mark-up. This assumption simplifies the proofs of the arguments but is not crucial for our general effect to hold. It is easy to verify that the assumption is satisfied for many commonly used demand functions such as the linear one considered in Section 4, CES, logit or Hotelling. ${ }^{11}$

\footnotetext{
${ }^{8}$ The explicit definition of $w_{E}^{\prime}$ is given in (4) in the Appendix.

${ }^{9} \mathrm{~A}$ similar assumption is imposed by Simpson and Wickelgren (2007) who assume $2\left(c_{I}-\right.$ $\left.c_{E}\right) D\left(\mathbf{p}\left(c_{I}, c_{I}\right) ; \gamma\right)>f$. It is easy to show that $w_{E}^{\prime} \rightarrow c_{I}$ if downstream firms are in perfect Bertrand competition. Therefore, our assumption adjusts the one by Simpson and Wickelgren (2007) to the case of differentiated products.

${ }^{10}$ See also the comments in the Conclusion.

${ }^{11}$ In general, it is well-known from the literature on strategic delegation or vertical restraints (e.g., Fershtman and Judd, 1987, or Bonanno and Vickers, 1985) that competing on the basis of higher costs than the true costs can be beneficial for a firm as it induces the rival firm to react less aggressively. However, this argument relies on the fact that, at the true input costs of firm $D_{i}$, a change in these costs has only a second-order effect on the optimal choice of firm $D_{i}$ but a first-order effect on the
} 


\section{The Effect in General Form}

We first look at the equilibrium in the downstream market when downstream firm $i$ faces a wholesale price $w_{i}$ while the downstream firm $j$ faces a wholesale price $w_{j}$. Firm $i$ 's profit function is

$$
\pi_{i}=D\left(p_{i}, p_{j ;} \gamma\right)\left(p_{i}-w_{i}\right)
$$

The first-order conditions are given by

$$
\frac{\partial D\left(p_{i}, p_{j ;} \gamma\right)}{\partial p_{i}}\left(p_{i}-w_{i}\right)+D\left(p_{i}, p_{j ;} \gamma\right)=0, \quad i \neq j, \quad i, j=1,2
$$

These first-order conditions characterize the equilibrium of the downstream game. Since we assume that $\left|\partial D\left(p_{i}, p_{j} ; \gamma\right) / \partial p_{i}\right|>\left|\partial D\left(p_{i}, p_{j} ; \gamma\right) / \partial p_{j}\right|$, the equilibrium is unique. Due to the other assumptions we have the natural properties that in equilibrium $d p_{i} / d w_{i}>0$ and $d p_{i} / d w_{j}>0$.

Since $\gamma \rightarrow 1$ implies $\partial D\left(p_{i}, p_{j}\right) / \partial p_{i} \rightarrow-\infty$, we obtain that profits become zero when products are undifferentiated. By contrast, when $\gamma=0$, implying that the downstream firms are independent monopolists, profits are largest.

In the following we assess for which levels of downstream competition the incumbent can profitably make use of exclusive contracting.

Lemma 1 If downstream competition is sufficiently strong, i.e., $\gamma \geq \widehat{\gamma}$, in any equilibrium both downstream firms sign the exclusive contract with the incumbent.

The lemma shows that the incumbent can profitably offer positive payments to the downstream firms for signing an exclusive contract if downstream competition is sufficiently intense. The intuition for this result is the following. Exclusive contracting enables the incumbent to earn monopoly profits. In addition, when downstream competition is intense, double marginalization is only a minor problem, implying that the incumbent's monopoly profits when inducing both firms to sign are relatively high. By contrast, the profits that the downstream firms can obtain when rejecting the contract decrease with the degree of downstream competition. Thus, the incumbent is able to profitably compensate the downstream firms for signing an exclusive contract when downstream competition is sufficiently intense.

The result of Lemma 1 is close to that by Simpson and Wickelgren (2007) who show that the incumbent can induce both downstream firms to sign exclusive contracts choice of the rival firm. By contrast, in our case $w_{c}$ is set according to a different maximization problem implying that it is biased upwards to a large extent. 
if downstream competition is almost perfect. We now move one step further and determine the optimal pricing decision of the entrant given both downstream firms have signed the contract.

Lemma 2 If $\underline{\gamma} \leq \gamma \leq \bar{\gamma}$, with $\underline{\gamma} \geq \widehat{\gamma}$, both signed downstream firms breach the exclusive contract and buy from the entrant at a wholesale price $w_{e}<c_{I}$.

Lemma 2 shows that both signed downstream firms are induced to breach at a wholesale price below $c_{I}$ if the degree of downstream competition is in an intermediate range. The intuition for this result is the following. Because breaching downstream firms have to pay expectation damages to the incumbent, they only breach when they can obtain sufficiently high profits in the downstream market. If the degree of downstream competition is in an intermediate range, each firm obtains sizable profits when breaching even if the rival firm also breaches. Therefore, the entrant needs to lower its wholesale price only to relatively small extent to bring about breach of both downstream firms instead of only one. Thus, in this intermediate range the entrant induces both firms to breach in equilibrium. Because downstream firms exert a negative externality on each other when breaching, which gets stronger with the degree of downstream competition, the entrant needs to price below the Bertrand duopoly price $c_{I}$ when $\gamma \geq \underline{\gamma}$. By contrast, when downstream competition is intense, the negative externality that breaching downstream firms exert on each other is so strong that each downstream firm can only obtain very small profits when breaching if the rival firm also breaches. In that case, as shown by Simpson and Wickelgren (2007), the entrant prefers to induce only one firm to breach.

From Lemma 2 we know, if $\underline{\gamma} \leq \gamma \leq \bar{\gamma}$ both signed downstream firms breach the exclusive contract and face a wholesale price $w_{e}<c_{I}$. If exclusive contracting was not allowed for, they would face a wholesale price equal to $c_{I}$. This gives us the following result.

Proposition 1 If $\underline{\gamma} \leq \gamma \leq \bar{\gamma}$, exclusive dealing has procompetitive effects.

The proposition shows that naked exclusion can indeed be welfare enhancing. For $\underline{\gamma} \leq \gamma \leq \bar{\gamma}$ the entrant induces both signed downstream firms to breach the contract by setting its wholesale price below $c_{I}$. Because downstream firms obtain the input good at a lower cost, they set lower prices to final consumers, which leads to an increase in consumer surplus and welfare. 
If products are sufficiently differentiated, i.e., $\gamma<\underline{\gamma}$, the possibility of exclusive contracting is competitively innocuous because either the incumbent cannot pay the downstream firms to accept exclusive contracts or the entrant can induce both downstream firms to breach at a price equal to $c_{I}$. In both cases welfare is unaffected by the possibility of exclusive contracting.

The effect of exclusive contracting on welfare is not clear for $\gamma>\bar{\gamma}$. The entrant sets a lower wholesale price to the single free downstream firm than it would set absent exclusive contracting. However, the captive downstream firm now faces a higher wholesale price. Thus, the downstream firms may set higher prices to final consumers than they would set absent exclusive contracting, in which case exclusive contracting would have anticompetitive effects. As shown by Simpson and Wickelgren (2007), the latter effect dominates if $\gamma \rightarrow 1$.

Our analysis shows that for a general class of demand functions naked exclusion can have procompetitive effects. However, the analysis so far does not allow us to draw conclusions on how large the specific regions for $\gamma$ are. This depends on the exact shape of the demand function. Therefore, we provide an example with a linear demand function in the next section.

\section{An Application with Linear Demand}

In this section we show that with a commonly used linear demand function exclusive contracting is procompetitive in a sizable range, in which the degree of product differentiation between the downstream firms is moderate.

We assume that demand is defined by the standard representative consumer model (see e.g., Vives, 1999), where a consumer's utility is given by

$$
U\left(q_{i}, q_{j}\right)=\left(q_{i}+q_{j}\right)-\frac{\left(q_{i}^{2}+q_{j}^{2}\right)+2 \gamma q_{i} q_{j}}{2}+v .
$$

Here, $q_{i}$ is the amount of consumption from downstream firm $i$ and $v$ is the consumption of an outside good whose marginal utility is normalized to one. The parameter $\gamma \in[0,1)$ again reflects the degree of product differentiation between the downstream firms. For $\gamma=0$ the two goods are independent, while for $\gamma \rightarrow 1$ they become perfect substitutes. If consumers maximize this utility subject to an income constraint, the inverse demand of downstream firm $i$ becomes $p_{i}=1-q_{i}-\gamma q_{j}$. It is straightforward to derive the Nash equilibrium in the downstream market by maximizing the downstream firms' profit for 
given wholesale prices $w_{i}$ and $w_{j}$. Downstream firm $i$ 's price in this equilibrium is given by

$$
p_{i}=\frac{(1-\gamma)(2+\gamma)+2 w_{i}+\gamma w_{j}}{(2-\gamma)(2+\gamma)}
$$

Both downstream firms receive positive demand only if their prices are sufficiently close to each other. If their prices strongly diverge, the higher priced downstream firm receives no demand, while the lower priced downstream firm captures the entire market. Specifically, downstream firm $i$ 's demand function is given by

$$
q_{i}=\left\{\begin{array}{ccrl}
1-p_{i} & \text { if } & 0 & <p_{i} \leq \frac{-1+\gamma+p_{j}}{\gamma}, \\
\frac{1-\gamma-p_{i}+\gamma p_{j}}{\left(1-\gamma^{2}\right)} & \text { if } & \frac{-1+\gamma+p_{j}}{\gamma} & <p_{i}<1-\gamma+\gamma p_{j} \\
0 & \text { if } & 1-\gamma+\gamma p_{j} & \leq p_{i}
\end{array}\right.
$$

We measure the entrant's efficiency advantage by $\theta$, where $c_{I}=\theta w^{m}\left(c_{E}\right)+(1-\theta) c_{E}{ }^{12}$ Here, $w^{m}\left(c_{E}\right)$ denotes the monopoly wholesale price when a firm's marginal cost is $c_{E}$, i.e., $w^{m}\left(c_{E}\right)=\left(1+c_{E}\right) / 2$. Hence, $\theta=0$ implies that the entrant has no efficiency advantage, while $\theta=1$ implies that the entrant's efficiency advantage is just drastic. To simplify the exposition we assume that $\theta \geq 0.121$ and $f=0 .{ }^{13}$ The first assumption is the equivalent to $c_{E}<w_{E}^{\prime}$ in the general demand case. Together with the second assumption it rules out the case in which entry is not profitable for $E$.

We first assess for which degrees of downstream competition the incumbent can profitably make use of exclusive contracting.

Lemma $\mathbf{1}^{\prime}$ If downstream competition is sufficiently strong, i.e., $\gamma \in[0.5,1)$, both downstream firms sign the exclusive contract with the incumbent.

Next, we determine the wholesale prices that the upstream firms set in equilibrium.

\section{Lemma $2^{\prime}$}

- The entrant sells to both downstream firms if (i) $\gamma \in[0,0.714)$ or (ii) $\gamma \in$ $[0.714,0.899) \wedge \theta \geq \hat{\theta}(\gamma)$.

- The entrant sells to one downstream firm if $(i) \gamma \in[0.714,0.899) \wedge \theta<\hat{\theta}(\gamma)$ or (ii) $\gamma \in[0.899,1)$.

- The entrant sets $w_{e}=c_{I}$ if $\gamma \in[0,0.618)$ and $w_{e}<c_{I}$ if $\gamma \in[0.618,1)$.

\footnotetext{
${ }^{12}$ This notation of the efficiency advantage follows Abito and Wright (2008).

${ }^{13}$ Here and in the following numbers are rounded up to three decimals.
} 
Here, $\hat{\theta}(\gamma):[0.714,0.899] \rightarrow[0.114,1]$ is a strictly increasing function, which is defined in equation (13) in the Appendix.

Congruent with Lemma 2, this lemma shows that dependent on the degree of product differentiation the entrant sells either to both or to one downstream firm. Additionally, the entrant's efficiency advantage plays a role when $\gamma \in[0.710,0.899)$. The entrant sells to both firms only if its efficiency advantage is sufficiently high. The intuition for this result is that the entrant's profit gain through the increase in demand when both firms breach is higher, the higher its efficiency advantage is, i.e., the lower its marginal costs are. Lemma $2^{\prime}$ further shows that increased downstream competition makes it more difficult for breaching firms to raise the damage payment so that it becomes necessary for the entrant to set its wholesale price below $c_{I}$ when $\gamma \geq 0.618$.

In the following, we assess the effect of exclusive contracting on welfare and consumer surplus. We compare the situation in which exclusive contracting is not possible with the equilibrium of our game. Here, we obtain the following result.

Proposition $\mathbf{1}^{\prime}$ The effect of exclusive contracting on welfare and consumer surplus is neutral when $\gamma \in[0,0.618)$, positive when (i) $\gamma \in[0.618,0.714$ ) or (ii) $\gamma \in[0.714,0.899)$ $\wedge \theta \geq \hat{\theta}(\gamma)$, and negative when (i) $\gamma \in[0.714,0.899) \wedge \theta<\hat{\theta}(\gamma)$ or (ii) $\gamma \in[0.899,1)$.

Proposition $1^{\prime}$ shows that with a commonly used demand function the effect of exclusive contracting is procompetitive in a sizable range in which downstream competition is moderate. The range is the larger, the larger the entrant's efficiency advantage is.

\section{Concluding Remarks}

In this paper we have shown that naked exclusion has procompetitive effects if downstream firms can breach exclusive contracts and competition between them is moderate. In this environment, both downstream firms sign the contract with the incumbent but also both downstream firms breach it and buy from the entrant later on. Because downstream firms have to pay expectation damages to the incumbent when breaching, the entrant must set its wholesale price sufficiently low. In particular, it must its wholesale price lower than absent exclusive contracting. As a consequence, downstream firms set lower prices to final consumers, which leads to a rise in consumer surplus and welfare.

Our analysis challenges the view that naked exclusion is anticompetitive or at best 
neutral - a conclusion emanating from the previous literature. We find that the effect of exclusive contracting absent efficiencies gains is only anticompetitive effects if downstream competition is very intense, whereas it is procompetitive if downstream competition is in an intermediate range. Hence, an important implication of our analysis is that exclusive dealing, although being intended by an incumbent firm as an entry deterring and therefore anticompetitive device, can have procompetitive effects. This speaks against a per se approach toward exclusive dealing.

A limitation of our model is that we assumed that entry costs are sufficiently small. We imposed this assumption to rule out the case in which the rival does not find it profitable to enter. Dropping this assumption would affect our results in that exclusive contracting would more readily lead to entry deterrence, and, therefore, render exclusive dealing more likely to be anticompetitive.

Following Simpson and Wickelgren (2007) we confined our attention to linear upstream prices - the case of two-part tariffs is much more complicated and therefore beyond the scope of this paper. If upstream firms could offer two-part tariffs the analysis would change in two respects. On the one hand, the incumbent would be able to avoid double marginalization implying that, when downstream firms sign exclusive deals, the incumbent earns the monopoly profit of the industry regardless of the degree of downstream competition. This makes exclusive dealing more profitable for the incumbent and raises the damage payment that downstream firms have to pay in case of contract breach. On the other hand, because the damage payment is higher in the two-part tariff case, the entrant likely needs to offer a lower wholesale price with exclusive dealing than without in order to render breaching profitable, given that negative fixed fees are not possible, e.g., due to moral hazard issues. Thus, exclusive dealing may again have procompetitive effects leading to even lower wholesale prices than in case of linear upstream pricing. Therefore, it seems plausible that the effect identified in this paper also carries over to the case of two-part tariffs. 


\section{A Proof of Lemma 1}

The proof proceeds in three steps. First, we calculate the compensation $x_{2}$, which the incumbent has to offer such that both downstream firms sign the exclusive contract. Second, we calculate the compensation $x_{1}$, which the incumbent has to offer such that exactly one downstream firm signs the exclusive contract. Then, we compare the net profits that the incumbent makes when it induces both, one or neither downstream firm to sign.

In the following, we denote the number of signed downstream firms by $S \in(0,1,2)$. The compensation $x_{2}$ must equal the additional profit that a downstream firm can make when rejecting the contract given the other downstream firm accepts the contract:

$$
x_{2}=\pi_{i \mid S=1}^{f}-\pi_{i \mid S=2}^{c}
$$

Here, $\pi_{i \mid S=1}^{f}$ denotes a downstream firm's profit when rejecting the contract while the rival downstream firm accepts it. $\pi_{i \mid S=2}^{c}$ denotes a downstream firm's profit when both accept it. For any compensation above $x_{2}$ accepting is strictly preferred by the downstream firms but $I$ makes lower profits.

If both downstream firms accept the exclusive contract, I's maximization problem is $^{14}$

$$
\max _{w_{i}, w_{j}} D\left(\mathbf{p}\left(w_{i}, w_{j}\right)_{;} \gamma\right)\left(w_{i}-c_{I}\right)+D\left(\mathbf{p}\left(w_{j}, w_{i}\right)_{;} \gamma\right)\left(w_{j}-c_{I}\right) .
$$

Since both downstream firms are symmetric, the optimal input prices, $w_{i}$ and $w_{j}$, are identical. Let us denote the solution to this problem $w_{i}^{*}=w_{j}^{*}=w_{I}$. When both downstream firms are captive, $I$ charges the monopoly wholesale price to them as it receives the same profits from them whether they breach or not. I's profit is then $\Pi_{I \mid S=2}=2 D\left(\mathbf{p}\left(w_{I}, w_{I}\right) ; \gamma\right)\left(w_{I}-c_{I}\right)$ and a downstream firm's profit, excluding the compensation payment, is $\pi_{i \mid S=2}^{c}=D\left(\mathbf{p}\left(w_{I}, w_{I}\right)_{;} \gamma\right)\left(p\left(w_{I}, w_{I}\right)-w_{I}\right)$.

Now suppose that one downstream firm rejects the contract. In the subsequent price game $I$ and $E$ compete for free downstream firms. Note that the captive downstream firm can also become free by breaching the contract. The standard Bertrand argument implies that $I$ offers a wholesale price $w_{f}=c_{I}$ and $E$ offers a wholesale price $w_{e} \leq c_{I}$ to free downstream firms. It could be optimal for $E$ to set $w_{e}<c_{I}$ to induce the captive downstream firm to breach. In order to verify this, we determine whether the captive

\footnotetext{
${ }^{14}$ In the following we use $D\left(p_{i}, p_{j} ; \gamma\right)$ as a short-cut for $\max \left\{0, D\left(p_{i}, p_{j} ; \gamma\right)\right\}$, that is, we do not explicitly write out if a demand function becomes zero. We do so to reduce the notational burden.
} 
downstream firm has an incentive to breach if $E$ sets $w_{e}=c_{I}$.

If the captive downstream firm does not breach the contract, its input price is $w_{c}$. Since $I$ gets the same profit from the captive downstream firm whether it breaches or not, $w_{c}$ is $\arg \max _{w} D\left(\mathbf{p}\left(w, c_{I}\right) ; \gamma\right)\left(w-c_{I}\right)$. This yields $w_{c}>c_{I}$. The captive downstream firm's profit when not breaching is $D\left(\mathbf{p}\left(w_{c}, c_{I}\right)_{;} \gamma\right)\left(p\left(w_{c}, c_{I}\right)-w_{c}\right)$. If the captive downstream firm instead breaches, its profit is $D\left(\mathbf{p}\left(c_{I}, c_{I}\right) ; \gamma\right)\left(p\left(c_{I}, c_{I}\right)-c_{I}\right)$ net the damage payment $D\left(\mathbf{p}\left(w_{c}, c_{I}\right) ; \gamma\right)\left(w_{c}-c_{I}\right)$ that it has to pay to $I$. Thus, breaching is profitable for the captive downstream firm if

$D\left(\mathbf{p}\left(c_{I}, c_{I}\right) ; \gamma\right)\left(p\left(c_{I}, c_{I}\right)-c_{I}\right)-D\left(\mathbf{p}\left(w_{c}, c_{I}\right) ; \gamma\right)\left(w_{c}-c_{I}\right) \geq D\left(\mathbf{p}\left(w_{c}, c_{I}\right) ; \gamma\right)\left(p\left(w_{c}, c_{I}\right)-w_{c}\right)$

or

$$
D\left(\mathbf{p}\left(c_{I}, c_{I}\right) ; \gamma\right)\left(p\left(c_{I}, c_{I}\right)-c_{I}\right) \geq D\left(\mathbf{p}\left(w_{c}, c_{I}\right) ; \gamma\right)\left(p\left(w_{c}, c_{I}\right)-c_{I}\right)
$$

which is satisfied by our assumption of Section 2. Hence, the captive downstream firm breaches the contract when $E$ sets $w_{e}=c_{I}$, so that it is optimal for $E$ to set $w_{e}=c_{I}$ and no lower wholesale price. $E$ finds it optimal to enter since by assumption $2\left(c_{I}-\right.$ $\left.c_{E}\right) D\left(\mathbf{p}\left(c_{I}, c_{I}\right)_{;} \gamma\right)>f$. As the captive downstream firm breaches, the downstream firm that did not sign the contract makes profits equal to $\pi_{i \mid S=1}^{f}=D\left(\mathbf{p}\left(c_{I}, c_{I}\right) ; \gamma\right)\left(p\left(c_{I}, c_{I}\right)-\right.$ $\left.c_{I}\right)$. We can deduce that $I$ has to offer

$$
x_{2}=D\left(\mathbf{p}\left(c_{I}, c_{I}\right) ; \gamma\right)\left(p\left(c_{I}, c_{I}\right)-c_{I}\right)-D\left(\mathbf{p}\left(w_{I}, w_{I}\right) ; \gamma\right)\left(p\left(w_{I}, w_{I}\right)-w_{I}\right)
$$

as compensation to each downstream firm for accepting the exclusive contract.

We now derive the compensation $x_{1}$ that $I$ has to offer to induce a single downstream firm to sign the exclusive contract. This compensation must equal the additional profit that a downstream firm can make when rejecting the exclusive contract provided the other downstream firm rejects it, i.e.,

$$
x_{1}=\pi_{i \mid S=0}^{f}-\pi_{i \mid S=1}^{c}
$$

Here, $\pi_{i \mid S=0}^{f}$ denotes a downstream firm's profit when both firms reject the contract, while $\pi_{i \mid S=1}^{c}$ denotes a downstream firm's profit when it signs the contract while the rival firm rejects it. If both downstream firms reject the contract, $E$ enters and the subsequent price game between the upstream firms results in the simple Bertrand duopoly wholesale prices, i.e., both upstream firms set wholesale prices equal to $c_{I}$. Thus, when both downstream firms reject the contract, they make profits equal to 
$\pi_{i \mid S=0}^{f}=D\left(\mathbf{p}\left(c_{I}, c_{I}\right) ; \gamma\right)\left(p\left(c_{I}, c_{I}\right)-c_{I}\right)$.

From the analysis above we know that a downstream firm's profit when it signs the contract, while the rival firm rejects it, is $\pi_{i \mid S=1}^{c}=D\left(\mathbf{p}\left(c_{I}, c_{I}\right) ; \gamma\right)\left(p\left(c_{I}, c_{I}\right)-c_{I}\right)-$ $D\left(\mathbf{p}\left(w_{c}, c_{I}\right) ; \gamma\right)\left(w_{c}-c_{I}\right)$. We can deduce that $I$ must offer

$$
x_{1}=D\left(\mathbf{p}\left(w_{c}, c_{I}\right) ; \gamma\right)\left(w_{c}-c_{I}\right)
$$

as compensation in order to induce one downstream firm to sign the exclusive contract.

We now compare the net profits that $I$ makes when inducing both downstream firms, one or neither downstream firm to sign the exclusive contract. When it induces both downstream firms to sign the exclusive contract, its net profit is

$2\left[D\left(\mathbf{p}\left(w_{I}, w_{I}\right) ; \gamma\right)\left(w_{I}-c_{I}\right)+D\left(\mathbf{p}\left(w_{I}, w_{I}\right) ; \gamma\right)\left(p\left(w_{I}, w_{I}\right)-w_{I}\right)-D\left(\mathbf{p}\left(c_{I}, c_{I}\right) ; \gamma\right)\left(p\left(c_{I}, c_{I}\right)-c_{I}\right)\right]$

It offers $x_{2}$ to each downstream firm as compensation for signing and receives the monopoly profit whether the downstream firms breach or not. When it induces one downstream firm to sign its net profit is zero. It pays $x_{1}$ as compensation for signing to one downstream firm, makes zero profit and receives a damage payment equal to $x_{1}$ because the signed downstream firm breaches. Since $I$ and $E$ are perfect Bertrand competitors but $E$ is more efficient, $I$ also makes zero net profit when inducing neither downstream firm to sign. Hence, $I$ makes use of exclusive contracting only if it is able to profitably induce both downstream firms to accept the exclusive contract, i.e., if

$$
D\left(\mathbf{p}\left(c_{I}, c_{I}\right) ; \gamma\right)\left(p\left(c_{I}, c_{I}\right)-c_{I}\right) \leq D\left(\mathbf{p}\left(w_{I}, w_{I}\right) ; \gamma\right)\left(p\left(w_{I}, w_{I}\right)-c_{I}\right)
$$

If the products are independent of each other, i.e., if $\gamma=0$, the left-hand side is larger than the right-hand side since no double marginalization takes place. To the converse, if the products are (almost) perfect substitutes, i.e., if $\gamma \rightarrow 1$, the left-hand side is zero since $p\left(c_{I}, c_{I}\right) \rightarrow c_{I}$, while the right-hand side is still positive since $p\left(w_{I}, w_{I}\right) \rightarrow w_{I}>c_{I}$. Therefore, there must exist an intermediate value of $\gamma$, denote it $\widehat{\gamma}$, such that both downstream firms sign the exclusive contract if $\gamma \geq \widehat{\gamma}$.

\section{B Proof of Lemma 2}

If both downstream firms signed the exclusive contract, $I$ charges the monopoly wholesale price $w_{c}=w_{I}$ to captive downstream firms and the Bertrand duopoly price $w_{f}=c_{I}$ 
to free downstream firms. Hence, $E$ is constraint in its pricing decision to free downstream firms by $w_{e} \leq c_{I}$. It may choose to induce both downstream firms or one downstream firm to breach. To induce both downstream firms to breach it needs to set a wholesale price $w_{e}=w_{E}$, where $w_{E}$ is defined by

$$
\begin{gathered}
D\left(\mathbf{p}\left(w_{E}, w_{E}\right) ; \gamma\right)\left(p\left(w_{E}, w_{E}\right)-w_{E}\right)-D\left(\mathbf{p}\left(w_{I}, w_{I}\right) ; \gamma\right)\left(w_{I}-c_{I}\right) \\
-D\left(\mathbf{p}\left(w_{I}, w_{E}\right)_{;} \gamma\right)\left(p\left(w_{I}, w_{E}\right)-w_{I}\right)=0 .
\end{gathered}
$$

$E$ optimally sets its wholesale price such that the downstream firms are indifferent between breaching or not. The first term denotes the profit that a downstream firm obtains when breaching provided the other downstream firm also breaches, the second term denotes the damage payment to $I$ in case of contract breach, which is half the profit that $I$ makes when none of the firms breaches, and the third term denotes the profit that a downstream firm makes when not breaching provided the other downstream firm breaches.

If $\gamma=0$, it is easy to see that there exists an equilibrium in which both downstream firms breach when $E$ sets $w_{E}=c_{I}$ since $D\left(p\left(c_{I}\right)\right)\left(p\left(c_{I}\right)-c_{I}\right)>D\left(p\left(w_{I}\right)\right)\left(p\left(w_{I}\right)-c_{I}\right)$. If, however, $\gamma$ becomes sufficiently large, $E$ needs to set $w_{E}<c_{I}$ for such an equilibrium to exist. To see this note that the first term of (3) goes to zero when downstream competition becomes very intense as $p\left(w_{E}, w_{E}\right) \rightarrow w_{E}$, while the two last terms of (3) are negative. Thus, when $\gamma$ is sufficiently large and $E$ sets $w_{E}=c_{I}$ the condition for both downstream firms to breach would be violated. $E$ then needs to set $w_{E}<c_{I}$, which increases the first term, does not change the second, and raises the third term, so that (3) is satisfied. It follows that there must exist a value of $\gamma$, which we denote $\check{\gamma}$, such that $E$ needs to set $w_{E}=c_{I}$ if $\gamma=\check{\gamma}$ and $w_{E}<c_{I}$ if $\gamma>\check{\gamma}$ for an equilibrium in which both downstream firms breach to exist.

We now turn to the case in which $E$ wants to induce just one downstream firm to breach. To do so, $E$ must set $w_{e}=w_{E}^{\prime}$, where $w_{E}^{\prime}$ is defined by

$$
\begin{gathered}
D\left(\mathbf{p}\left(w_{E}^{\prime}, w_{I}\right) ; \gamma\right)\left(p\left(w_{E}^{\prime}, w_{I}\right)-w_{E}^{\prime}\right)-2 D\left(\mathbf{p}\left(w_{I}, w_{I}\right) ; \gamma\right)\left(w_{I}-c_{I}\right) \\
+D\left(\mathbf{p}\left(w_{I}, w_{E}^{\prime}\right) ; \gamma\right)\left(w_{I}-c_{I}\right)-D\left(\mathbf{p}\left(w_{I}, w_{I}\right) ; \gamma\right)\left(p\left(w_{I}, w_{I}\right)-w_{I}\right)=0 .
\end{gathered}
$$

The first term denotes the profit that a downstream makes when breaching provided the other downstream firm does not breach, the second and the third term denote the damage payment to $I$ in case of contract breach, which is the profit that $I$ makes if the downstream firm does not breach minus the profit that $I$ makes when it breaches, and 
the fourth term denotes the profit that a downstream firm makes when not breaching provided the other firm does not breach.

Two cases can now occur, namely, either $w_{E}^{\prime} \geq w_{E}$ or $w_{E}^{\prime}<w_{E}$. If $w_{E}^{\prime} \geq w_{E}$, then in any subgame perfect equilibrium one downstream firm breaches if $E$ sets $w_{e} \in\left(w_{E}, w_{E}^{\prime}\right]$ and both downstream firms breach if $E$ sets $w_{e} \leq w_{E}$. If, however, $w_{E}^{\prime}<w_{E}$, there are two subgame perfect equilibria if $E$ sets $w_{e} \in\left(w_{E}^{\prime}, w_{E}\right]$, with either both downstream firms or no downstream firm breaching. By assumption the downstream firms are able to coordinate themselves to play the equilibrium that is Pareto dominant from their perspective. Here, the Pareto dominant equilibrium is the equilibrium in which no downstream firm breaches as each firm exerts a negative externality on the other firm when breaching. It follows that $E$ can only induce both downstream firms to breach when setting $w_{e}=w_{E}^{\prime}$.

We will now show that there always exists a region in which $E$ must set $w_{e}<c_{I}$ to induce both downstream firms to breach. We do so by showing that at $\gamma=\check{\gamma}$, at which $w_{E}=c_{I}, w_{E}^{\prime}$ lies below $c_{I}$. If $w_{E}^{\prime}$ lies below $c_{I}$ at $\gamma=\check{\gamma}, E$ must set $w_{e}<c_{I}$ to induce both downstream firms to breach. By our assumption on $f, E$ would nevertheless find it profitable to enter.

We know that at $\check{\gamma}$ equation (3) can be written as

$$
\begin{gathered}
D\left(\mathbf{p}\left(c_{I}, c_{I}\right) ; \check{\gamma}\right)\left(p\left(c_{I}, c_{I}\right)-c_{I}\right)-D\left(\mathbf{p}\left(w_{I}, w_{I}\right) ; \check{\gamma}\right)\left(w_{I}-c_{I}\right) \\
-D\left(\mathbf{p}\left(w_{I}, c_{I}\right) ; \check{\gamma}\right)\left(p\left(w_{I}, c_{I}\right)-w_{I}\right)=0 .
\end{gathered}
$$

We need to show that $w_{E}^{\prime}$ is lower than $c_{I}$ when (5) is fulfilled, which is equivalent to the left-hand side of (4) being negative when $w_{E}^{\prime}=c_{I}$, i.e.,

$$
\begin{gathered}
D\left(\mathbf{p}\left(c_{I}, w_{I}\right) ; \check{\gamma}\right)\left(p\left(c_{I}, w_{I}\right)-c_{I}\right)-2 D\left(\mathbf{p}\left(w_{I}, w_{I}\right) ; \check{\gamma}\right)\left(w_{I}-c_{I}\right) \\
+D\left(\mathbf{p}\left(w_{I}, c_{I}\right) ; \check{\gamma}\right)\left(w_{I}-c_{I}\right)-D\left(\mathbf{p}\left(w_{I}, w_{I}\right) ; \check{\gamma}\right)\left(p\left(w_{I}, w_{I}\right)-w_{I}\right)<0
\end{gathered}
$$

Subtracting the left-hand side of (6) from the left-hand side of (5) and rearranging the terms, we obtain

$$
\begin{gathered}
D\left(\mathbf{p}\left(c_{I}, c_{I}\right) ; \check{\gamma}\right)\left(p\left(c_{I}, c_{I}\right)-c_{I}\right)+D\left(\mathbf{p}\left(w_{I}, w_{I}\right) ; \check{\gamma}\right)\left(p\left(w_{I}, w_{I}\right)-c_{I}\right) \\
-D\left(\mathbf{p}\left(c_{I}, w_{I}\right) ; \check{\gamma}\right)\left(p\left(c_{I}, w_{I}\right)-c_{I}\right)-D\left(\mathbf{p}\left(w_{I}, c_{I}\right) ; \check{\gamma}\right)\left(p\left(w_{I}, c_{I}\right)-c_{I}\right)
\end{gathered}
$$

which needs to be positive for our result to hold. We can rewrite the last expression as 


$$
\begin{gathered}
D\left(\mathbf{p}\left(c_{I}, c_{I}\right) ; \check{\gamma}\right)\left(p\left(c_{I}, c_{I}\right)-c_{I}\right)-D\left(\mathbf{p}\left(w_{I}, c_{I}\right) ; \check{\gamma}\right)\left(p\left(w_{I}, c_{I}\right)-c_{I}\right) \\
+D\left(\mathbf{p}\left(w_{I}, w_{I}\right) ; \check{\gamma}\right)\left(w_{I}-c_{I}\right)+D\left(\mathbf{p}\left(w_{I}, w_{I}\right) ; \check{\gamma}\right)\left(w_{I}-c_{I}\right) \\
-D\left(\mathbf{p}\left(c_{I}, w_{I}\right) ; \check{\gamma}\right)\left(w_{I}-c_{I}\right)-D\left(\mathbf{p}\left(w_{I}, w_{I}\right) ; \check{\gamma}\right)\left(w_{I}-c_{I}\right) \\
+D\left(\mathbf{p}\left(w_{I}, w_{I}\right)_{;} \check{\gamma}\right)\left(p\left(w_{I}, w_{I}\right)-w_{I}\right)-D\left(\mathbf{p}\left(c_{I}, w_{I}\right)_{;} \check{\gamma}\right)\left(\left(p\left(c_{I}, w_{I}\right)-w_{I}\right) .\right.
\end{gathered}
$$

We start with the first line of (7). We know that (3) is just satisfied at $\check{\gamma}$, i.e.,

$D\left(\mathbf{p}\left(c_{I}, c_{I}\right) ; \check{\gamma}\right)\left(p\left(c_{I}, c_{I}\right)-c_{I}\right)=D\left(\mathbf{p}\left(w_{I}, w_{I}\right) ; \check{\gamma}\right)\left(w_{I}-c_{I}\right)+D\left(\mathbf{p}\left(w_{I}, c_{I}\right) ; \check{\gamma}\right)\left(p\left(w_{I}, c_{I}\right)-w_{I}\right)$

Inserting the right-hand side of (8) into the first line of (7) gives

$$
\begin{gathered}
D\left(\mathbf{p}\left(w_{I}, w_{I}\right) ; \check{\gamma}\right)\left(w_{I}-c_{I}\right)+D\left(\mathbf{p}\left(w_{I}, c_{I}\right) ; \check{\gamma}\right)\left(p\left(w_{I}, c_{I}\right)-w_{I}\right) \\
-D\left(\mathbf{p}\left(w_{I}, c_{I}\right) ; \check{\gamma}\right)\left(w_{I}-c_{I}\right)-D\left(\mathbf{p}\left(w_{I}, c_{I}\right) ; \check{\gamma}\right)\left(p\left(w_{I}, c_{I}\right)-w_{I}\right) \\
=\left[D\left(\mathbf{p}\left(w_{I}, w_{I}\right) ; \check{\gamma}\right)-D\left(\mathbf{p}\left(w_{I}, c_{I}\right) ; \check{\gamma}\right)\right]\left(w_{I}-c_{I}\right)>0 .
\end{gathered}
$$

The first line of (7) is therefore positive since a downstream firm's demand increases in the rival firm's price, i.e. $D\left(\mathbf{p}\left(w_{I}, w_{I}\right) ; \check{\gamma}\right)>D\left(\mathbf{p}\left(w_{I}, c_{I}\right) ; \check{\gamma}\right)$.

Now we turn to the second and third line. In case both downstream firms have signed the contract, we know that $I$ maximizes

$$
\max _{w_{i}, w_{j}} D\left(\mathbf{p}\left(w_{i}, w_{j}\right) ; \check{\gamma}\right)\left(w_{i}-c_{I}\right)+D\left(\mathbf{p}\left(w_{j}, w_{i}\right) ; \check{\gamma}\right)\left(w_{j}-c_{I}\right)
$$

and that $w_{I}$ is the solution to this maximization problem. Therefore, line 2 of $(7)$ equals $I$ 's monopoly profit when it charges $w_{i}=w_{j}=w_{I}$, while line 3 of (7) displays $I$ 's profit when making a suboptimal pricing decision, namely $w_{i}=c_{I}$ and $w_{j}=w_{I}$. It follows that line 2 and 3 of (7) are positive by the definition of $w_{I}$.

Closer inspection of line 4 reveals that it is positive if a downstream firm makes higher profits when setting its price on the basis of its true input cost - call it $c^{\prime}$ instead of a lower input cost - call it $c<c^{\prime}$. When basing its pricing decision on different costs, a downstream firm does not only change its own price but also its rival's price. Generally optimality of the cost-based decision requires

$$
\max _{c} D(\mathbf{p}(c, y) ; \check{\gamma})\left(p(c, y)-c^{\prime}\right)
$$

which gives a first-order condition of 


$$
\begin{gathered}
D(\mathbf{p}(c, y) ; \check{\gamma}) \frac{\partial p(c, y)}{\partial c}+\frac{\partial D(\mathbf{p}(c, y) ; \check{\gamma})}{\partial p(c, y)} \frac{\partial p(c, y)}{\partial c}\left(p(c, y)-c^{\prime}\right) \\
+\frac{\partial D(\mathbf{p}(c, y) ; \check{\gamma})}{\partial p(y, c)} \frac{\partial p(y, c)}{\partial c}\left(p(c, y)-c^{\prime}\right)=0 .
\end{gathered}
$$

Further, the optimality condition for the downstream price $p(c, y)$, resulting from the maximization problem

$$
\arg \max _{p(c, y)} D(\mathbf{p}(c, y) ; \check{\gamma})(p(c, y)-c)
$$

is given by

$$
\frac{\partial D(\mathbf{p}(c, y) ; \check{\gamma})}{\partial p(c, y)}(p(c, y)-c)+D(\mathbf{p}(c, y) ; \check{\gamma})=0
$$

and can be rewritten as

$$
D(\mathbf{p}(c, y) ; \check{\gamma})+\frac{\partial D(\mathbf{p}(c, y) ; \check{\gamma})}{\partial p(c, y)} p(c, y)=\frac{\partial D\left(\mathbf{p}(c, y)_{;} \check{\gamma}\right)}{\partial p(c, y)} c .
$$

Inserting (10) into (9) gives

$$
\frac{\partial D(\mathbf{p}(c, y) ; \check{\gamma})}{\partial p(c, y)} \frac{\partial p(c, y)}{\partial c}\left(c-c^{\prime}\right)+\frac{\partial D(\mathbf{p}(c, y) ; \check{\gamma})}{\partial p(y, c)} \frac{\partial p(y, c)}{\partial c}\left(p(c, y)-c^{\prime}\right)=0
$$

The second term is positive while the first term depends on the sign of $c-c^{\prime}$. Since $\partial D(\mathbf{p}(c, y) ; \check{\gamma}) / \partial p(c, y)$ is negative and $\partial p(c, y) / \partial c$ is positive, optimality requires that $c>c^{\prime}$. Hence, it can never be better for a downstream firm to set a price on the basis of a lower input cost than its true input cost, which implies that line 4 of (7) must be positive.

We can conclude that the expression in (7) is positive, implying $w_{E}^{\prime}<c_{I}$ at $\check{\gamma}$. By continuity there exists a region around $\check{\gamma}$, such that $w_{e}<c_{I}$. Let us denote the lower bound of this region $\widetilde{\gamma}$ and the upper bound $\bar{\gamma}$, with $\widetilde{\gamma}<\check{\gamma}<\bar{\gamma}$.

Finally, we need to show that $\check{\gamma}$ lies indeed above $\widehat{\gamma}$. First note that at $\gamma=\widehat{\gamma}$ condition (2) can be written as

$$
D\left(\mathbf{p}\left(c_{I}, c_{I}\right) ; \widehat{\gamma}\right)\left(p\left(c_{I}, c_{I}\right)-c_{I}\right)=D\left(\mathbf{p}\left(w_{I}, w_{I}\right) ; \widehat{\gamma}\right)\left(p\left(w_{I}, w_{I}\right)-w_{I}\right)+D\left(\mathbf{p}\left(w_{I}, w_{I}\right) ; \widehat{\gamma}\right)\left(w_{I}-c_{I}\right)
$$

However, $\check{\gamma}$ is defined by

$$
D\left(\mathbf{p}\left(c_{I}, c_{I}\right) ; \check{\gamma}\right)\left(p\left(c_{I}, c_{I}\right)-c_{I}\right)=D\left(\mathbf{p}\left(w_{I}, c_{I}\right) ; \check{\gamma}\right)\left(p\left(w_{I}, c_{I}\right)-w_{I}\right)+D\left(\mathbf{p}\left(w_{I}, w_{I}\right) ; \check{\gamma}\right)\left(w_{I}-c_{I}\right)
$$


The difference between (11) and (12) is the first term on the two right-hand sides. We know that $D\left(\mathbf{p}\left(w_{I}, c_{I}\right) ; \gamma\right)\left(p\left(w_{I}, c_{I}\right)-w_{I}\right)<D\left(\mathbf{p}\left(w_{I}, w_{I}\right) ; \gamma\right)\left(p\left(w_{I}, w_{I}\right)-w_{I}\right)$. In addition, we know that for $\gamma=0$, the left-hand sides of (11) and (12) are bigger than the respective right-hand sides while for $\gamma \rightarrow 1$, the reverse holds true. Since $\widehat{\gamma}$ is defined as the largest $\gamma$ for which (11) holds, it follows that for $\check{\gamma}$ to fulfill (12) we must have $\check{\gamma}>\widehat{\gamma}$. At last, we define $\underline{\gamma} \equiv \max [\widehat{\gamma}, \widetilde{\gamma}]$.

\section{Proof of Lemma $1^{\prime}$}

From the analysis above we know that $I$ makes use of exclusive contracting if the monopoly profit that it earns when both downstream firms sign is higher than twice the compensation $\left(x_{2}=\pi_{i \mid S=2}^{c}-\pi_{i \mid S=1}^{f}\right)$ that it has to offer to each downstream firm for signing. I's monopoly wholesale price is $w_{I}=\left(1+c_{I}\right) / 2$. Thus, when both downstream firms sign the contract, $I$ obtains a monopoly profit equal to $\Pi_{I}\left(w_{I}, w_{I}\right)=$ $\left(1-c_{I}\right)^{2} /(2(1+\gamma)(2-\gamma))$ and each downstream firm makes profits equal to $\pi_{i \mid S=2}^{c}=$ $\left(1-c_{I}\right)^{2}(1-\gamma) /\left(4(1+\gamma)(2-\gamma)^{2}\right)$. We know from the previous analysis that a single captive downstream firm is induced to breach when $E$ sets $w_{e}=c_{I}$. Therefore, a downstream firm's profit when rejecting the exclusive contract, given the rival firm accepts it, is $\pi_{i \mid S=1}^{f}=\left(1-c_{I}\right)^{2}(1-\gamma) /\left((2-\gamma)^{2}(1+\gamma)\right)$. We can deduce that $I$ makes effective use of exclusive contracting if

$$
\Pi_{I}\left(w_{I}, w_{I}\right)-2\left[\pi_{i \mid S=2}^{c}-\pi_{i \mid S=1}^{f}\right]=\frac{\left(1-c_{I}\right)^{2}}{2(1+\gamma)(2-\gamma)}-\frac{3\left(1-c_{I}\right)^{2}(1-\gamma)}{2(2-\gamma)^{2}(1+\gamma)} \geq 0
$$

It is easy to verify that the inequality holds for $\gamma \in[0.5,1)$.

\section{Proof of Lemma $2^{\prime}$}

From the previous lemma we know that $I$ does not offer exclusive contracts to the downstream firms if $\gamma \in[0,0.5)$. All downstream firms are free in that case. The subsequent price game between the upstream firms results in the simple Bertrand duopoly prices. Both downstream firms buy from $E$ at $w_{e}=c_{I}>c_{E}$.

If $\gamma \in[0.5,1)$, we know that $I$ offers exclusive contracts that both downstream firms sign. I charges the monopoly wholesale price, $w_{c}=w_{I}$, to captive downstream firms and the Bertrand duopoly price $w_{f}=c_{I}$ to free downstream firms, i.e., those firms that breach the contract later on. It follows that $E$ is constraint in its pricing decision to 
free downstream firms by $w_{e} \leq c_{I}$. An equilibrium exists, in which both downstream firms breach, when $E$ sets a wholesale price $w_{E}$ such that condition (3) is met. Each downstream firm needs to be indifferent between breaching or not, given the rival firm breaches. If firm $i$ adheres to the contract while firm $j$ breaches, firm $i$ only receives positive demand if $p_{i}$ and $p_{j}$ are sufficiently close, i.e., if $\left(-1+\gamma+p_{i}\right) / \gamma<p_{j}$. If $p_{i}$ and $p_{j}$ are sufficiently close, condition (3) is satisfied for

$$
\begin{aligned}
w_{E_{1}}= & \frac{1}{4\left(2-\gamma^{2}\right)\left(2-2 \gamma-\gamma^{2}\right)}\left[4 \gamma^{4}+2\left(3+c_{E}\right) \gamma^{3}+\theta\left(1-c_{E}\right)\left(\gamma^{3}-2 \gamma\right)-4\left(3+c_{E}\right) \gamma\right. \\
& \left.-\left(1-c_{E}\right)(2-\theta)(2+\gamma) \sqrt{(1-\gamma)\left(2-\gamma^{2}\right)\left(6-8 \gamma-\gamma^{2}+2 \gamma^{3}\right)}+16\left(1-\gamma^{2}\right)\right]
\end{aligned}
$$

where we replaced $c_{I}$ by $\theta w^{m}\left(c_{E}\right)+(1-\theta) c_{E}$.

If downstream competition is relatively strong, firm $i$ receives no demand when adhering to the contract, given firm $j$ breaches. In this case, we are in the region $0<p_{j} \leq\left(-1+\gamma+p_{i}\right) / \gamma$ and condition (3) is satisfied for

$$
w_{E_{2}}=1-\frac{\left(1-c_{E}\right)(2-\theta) \sqrt{(2-\gamma)(1-\gamma)}}{4(1-\gamma)}
$$

We now determine for which regions of $\gamma$ the wholesale prices $w_{E_{1}}$ and $w_{E_{2}}$ are relevant. Determining $p_{i}$ and $p_{j}$ for the case in which firm $j$ breaches and buys at $w_{E_{1}}$ while firm $i$ adheres to the contract and buys at $w_{c}=w_{I}$, and inserting these prices into $\left(-1+\gamma+p_{i}\right) / \gamma<p_{j}$, gives that $w_{E_{1}}$ is relevant for $\gamma \in[0.5,0.710)$. Similarly, by determining $p_{i}$ and $p_{j}$ for the case in which firm $j$ buys at $w_{E_{2}}$ and firm $i$ buys at $w_{c}=w_{I}$, and inserting these prices into $p_{j} \leq\left(-1+\gamma+p_{i}\right) / \gamma$, gives that $w_{E_{2}}$ is relevant for $\gamma \in[0.710,1){ }^{15}$

For an equilibrium to exist, in which exactly one downstream firm breaches the exclusive contract, $E$ must set a wholesale price $w_{E}^{\prime}$ such that condition (4) is met. A downstream firm needs to be indifferent between breaching or not provided the rival firm does not breach. If the captive firm $j$ still receives positive demand when firm $i$ breaches the contract, condition (4) is fulfilled for

$$
\begin{aligned}
w_{E_{1}}^{\prime}= & \frac{1}{4\left(2-\gamma^{2}\right)^{2}}\left[16-8 \gamma-16 \gamma^{2}+3 \gamma^{3}+4 \gamma^{4}+\left(4 \gamma-\frac{3}{2} \gamma^{3}\right)\left(c_{E}(2-\theta)+\theta\right)\right. \\
& \left.-\frac{1}{2}(2-\theta)\left(1-c_{E}\right)(2+\gamma) \sqrt{48-96 \gamma+12 \gamma^{2}+76 \gamma^{3}-31 \gamma^{4}-16 \gamma^{5}+8 \gamma^{6}}\right] .
\end{aligned}
$$

\footnotetext{
${ }^{15}$ The reason why the threshold values for the two regions coincide at $\gamma=0.710$ is that firm $i$ 's profit function has a kink but no jump at $\left(-1+\gamma+p_{i}\right) / \gamma=p_{j}$. Thus, the wholesale prices $w_{E_{1}}$ and $w_{E_{2}}$ are identical at the value where one switches from one region to the other.
} 
If the captive firm $j$ receives no demand when firm $i$ breaches the contract, condition (4) is satisfied for

$$
w_{E_{2}}^{\prime}=\frac{2(1-\gamma)^{2}\left(2-\gamma^{2}\right)+c_{E}\left(2+(1-\gamma) \gamma^{2}\right)(2-\theta)+\left(2+\gamma^{2}-\gamma^{3}\right) \theta}{2(2-\gamma)^{2} \gamma(1+\gamma)}
$$

In the same way as above we can determine for which region of $\gamma$ the two wholesale prices are relevant. Here, we obtain that $w_{E_{1}}^{\prime}$ is relevant for $\gamma \in[0.5,0.706)$ and $w_{E_{2}}^{\prime}$ is relevant for $\gamma \in[0.706,1]$.

It is straightforward to verify that $w_{E_{1}}^{\prime}$ lies below $w_{E_{1}}$ for $\gamma \in[0.5,0.706)$. Thus, when $E$ charges $w_{E_{1}}^{\prime}$, in the unique equilibrium both downstream firms breach the exclusive contract. When $E$ charges $w_{e} \in\left(w_{E_{1}}^{\prime}, w_{E_{1}}\right]$, there are two equilibria with either both downstream firms or no downstream firm breaching the exclusive contract. By assumption the downstream firms play the Pareto dominant equilibrium which is the one in which no downstream firm breaches. It follows that it is optimal for $E$ to charge $w_{e}=\min \left[w_{E_{1}}^{\prime}, c_{I}\right]$, inducing both downstream firms to breach. We find that $w_{E_{1}}^{\prime}$ lies above $c_{I}$ for $\gamma \in[0.5,0.618)$. Since $c_{I}>c_{E}, E$ sets $w_{e}=c_{I}$ and induces both downstream firms to breach if $\gamma \in[0.5,0.618)$. To analyze whether it is profitable for $E$ to set $w_{E_{1}}^{\prime}$ if $\gamma \in[0.618,0.706)$ we need to compare $w_{E_{1}}^{\prime}$ with $c_{E}$. Since $w_{E_{1}}^{\prime}$ is strictly decreasing in $\gamma$, a sufficient condition for $w_{E_{1}}^{\prime}$ to be larger than $c_{E}$ provided $\gamma \in[0.618,0.706)$ is that $w_{E_{1}}^{\prime}>c_{E}$ at $\gamma=0.706$. We find that $w_{E_{1}}^{\prime}>c_{E}$ at $\gamma=0.706$ if $\theta \geq 0.121$, which is fulfilled by assumption. Therefore, in equilibrium $E$ sets $w_{e}=w_{E_{1}}^{\prime}$ and induces both downstream firms to breach if $\gamma \in[0.618,0.706)$.

We now turn to the case in which $\gamma \in[0.706,0.710)$. Here the relevant wholesale prices are $w_{E_{2}}^{\prime}$ and $w_{E_{1}}$. By comparing these wholesale prices we find that $w_{E_{2}}^{\prime}<w_{E_{1}}$, which again implies that for $w_{e} \in\left(w_{E_{2}}^{\prime}, w_{E_{1}}\right]$ multiple equilibria exist in which either both or no downstream firm breaches the contract. By the same argument as above, the downstream firms coordinate themselves on the equilibrium in which none of them breaches since this is Pareto dominant. It is easy to verify that $w_{E_{2}}^{\prime}$ is smaller than $c_{I}$ and that it exceeds $c_{E}$ for $\gamma \in[0.706,0.710)$ if $\theta \geq 0.121$. Therefore, it is optimal for $E$ to set $w_{e}=w_{E_{2}}^{\prime}$, inducing both downstream firms to breach if $\gamma \in[0.706,0.710)$.

Finally, we turn to the case in which $\gamma \in[0.710,1)$. $E$ can choose between $w_{E_{2}}$ and $w_{E_{2}}^{\prime}$. For $\gamma \in[0.710,0.714)$ we find that $w_{E_{2}}^{\prime}<w_{E_{2}}$. In the same way as above, we obtain that it is optimal for $E$ to set $w_{e}=w_{E_{2}}^{\prime}$ and induce both downstream firms to breach if $\theta \geq 0.118$, which is fulfilled by assumption. To determine whether it is more profitable for $E$ to set $w_{E_{2}}$ or $w_{E_{2}}^{\prime}$ when $\gamma \in[0.714,1)$, we compare the profits 
that $E$ makes in each case. The profit that $E$ makes when setting $w_{E_{2}}$, inducing both downstream firms to breach, is

$\Pi_{E}\left(w_{E_{2}}, w_{E_{2}}\right)=\frac{\left(1-c_{E}\right)^{2}(2-\theta) \sqrt{(2-\gamma)(1-\gamma)}[4(1-\gamma)-(2-\theta) \sqrt{(2-\gamma)(1-\gamma)}]}{8(2-\gamma)(1-\gamma)^{2}(1+\gamma)}$,

and the profit that $E$ makes when setting $w_{E_{2}}^{\prime}$, inducing one downstream firm to breach, is

$$
\Pi_{E}\left(w_{E_{2}}^{\prime}, w_{I}\right)=\frac{\left(1-c_{E}\right)^{2}(2-\theta)\left(2\left(2-\gamma^{2}\right)(1-\gamma)^{2}-\theta\left(2+\gamma^{2}-\gamma^{3}\right)\right)}{8(2-\gamma)^{2} \gamma^{2}(1+\gamma)} .
$$

By solving $\Pi_{E}\left(w_{E_{2}}, w_{E_{2}}\right)=\Pi_{E}\left(w_{E_{2}}^{\prime}, w_{I}\right)$ for $\theta$ we obtain

$$
\hat{\theta}(\gamma)=\frac{2(2-(2-\gamma) \gamma(3+\gamma(1-2 \sqrt{(2-\gamma)(1-\gamma)}-(2-\gamma) \gamma)))}{2-(2-\gamma) \gamma(1+2 \gamma)}
$$

For all $\theta>\hat{\theta}(\gamma)$ we have that $\Pi_{E}\left(w_{E_{2}}, w_{E_{2}}\right)>\Pi_{E}\left(w_{E_{2}}^{\prime}, w_{I}\right)$ and vice versa. It is straightforward to verify that $\hat{\theta}(\gamma)$ is strictly increasing in $\gamma$. Inserting $\gamma=0.714$ into $\hat{\theta}(\gamma)$ yields $\hat{\theta}(0.714)=0.114$, while $\hat{\theta}(\gamma)$ equals 1 when $\gamma=0.899$.

We now have to show that it is profitable for $E$ to enter and set either $w_{E_{2}}$ or $w_{E_{2}}^{\prime}$ if $\gamma \in[0.714,1)$. As $w_{E_{2}}^{\prime}$ is relevant when $E$ 's efficiency advantage is low we only need to compare $w_{E_{2}}^{\prime}$ with $c_{E}$. Since $w_{E_{2}}^{\prime}$ is strictly increasing in $\gamma$, a sufficient condition for $w_{E_{2}}^{\prime}$ to be larger than $c_{E}$ provided $\gamma \in[0.714,1)$ is that $w_{E_{2}}^{\prime}>c_{E}$ at $\gamma=0.714$. We find that $w_{E_{2}}^{\prime}>c_{E}$ at $\gamma=0.714$ for $\theta \geq 0.114$, which is again fulfilled by our assumption that $\theta \geq 0.121$. Therefore, when $\gamma \in[0.714,0.899)$ and $\theta<\hat{\theta}(\gamma)$, it is optimal for $E$ to set $w_{e}=w_{E_{2}}^{\prime}$, inducing one downstream firm to breach. Whereas, when $\gamma \in[0.714,0.899)$ and $\theta \geq \hat{\theta}(\gamma)$, it is optimal for $E$ to set $w_{e}=w_{E_{2}}$, inducing both downstream firms to breach. When $\gamma \in[0.899,1)$, it is always optimal for $E$ to set $w_{e}=w_{E_{2}}^{\prime}$, inducing one downstream firm to breach.

\section{E Proof of Proposition $1^{\prime}$}

When exclusive dealing is not possible, $E$ enters and the subsequent price game between the upstream firms results in the simple Bertrand duopoly prices, i.e., both upstream firms set wholesale prices equal to $c_{I}$. When exclusive contracting is possible and $\gamma \in[0,0.5)$, both downstream firms decline $I$ 's offer for an exclusive contract. When $\gamma \in[0.5,0.618)$, both downstream firms sign the exclusive contract, but are induced to breach if $E$ sets $w_{e}=c_{I}$. In both these cases the outcome is unaffected by the 
possibility of exclusive contracting.

When (i) $\gamma \in[0.618,0.714)$ or (ii) $\gamma \in[0.714,0.899) \wedge \theta \geq \hat{\theta}(\gamma)$, both downstream firms sign the exclusive contract and are induced to breach at a price $w_{e}<c_{I}$. Because the downstream firms acquire the input good at a lower price, they set lower prices to final consumers. As a consequence, consumer surplus and welfare rise.

Finally, when (i) $\gamma \in[0.714,0.899) \wedge \theta<\hat{\theta}(\gamma)$ or (ii) $\gamma \in[0.899,1)$, both downstream firms sign the exclusive contract and $E$ induces one downstream firm to breach at a wholesale price $w_{e}<c_{I}$. The breaching downstream firm sets a price to final consumers, $p_{e d}=\left(c_{I}+2 \gamma-1\right) / 2 \gamma$, that leads to monopolization of the downstream market. Because $p_{e d}$ is higher than the price that the downstream firms would set absent exclusive dealing, $p_{\text {ned }}=\left(c_{I}-\gamma+1\right) /(2-\gamma)$, consumer surplus and welfare fall.

\section{References}

[1] Abito, Jose M., and Julian Wright (2008), "Exclusive Dealing with Imperfect Downstream Competition", International Journal of Industrial Organization, 26, 227246.

[2] Aghion, Philippe, and Patrick Bolton (1987), "Contracts as a Barrier to Entry", American Economic Review, 77, 388-401.

[3] Bonanno, Giacomo and John Vickers (1988), "Vertical Separation", Journal of Industrial Economics, 36, 257-265.

[4] Bernheim, B. Douglas, and Michael D. Whinston (1998), "Exclusive Dealing", Journal of Political Economy, 106, 64-103.

[5] Bork, Robert H. (1978), The Antitrust Paradox, New York: Basic Books.

[6] Brodley, Joseph F. and Ching-to Albert Ma (1993), "Contract Penalties, Monopolizing Strategies, and Antitrust Policy", Stanford Law Review, 45, 1161-1213.

[7] Fershtman, Chaim, and Kenneth L. Judd (1987), "Equilibrium Incentives in Oligopoly", American Economic Review, 77, 927-940.

[8] Fumagalli, Chiara, and Massimo Motta (2006), "Exclusive Dealing and Entry, when Buyers Compete", American Economic Review, 96, 785-795. 
[9] Innes, Robert and Richard J. Sexton (1994), "Strategic Buyers and Exclusionary Contracts", American Economic Review, 83, 566-584.

[10] Kitamura, Hiroshi (2010), "Exclusionary Vertical Contracts with Multiple Entrants", International Journal of Industrial Organization, 28, 213-219.

[11] Mathewson, G. Frank and Ralph A. Winter (1987), "The Competitive Effects of Vertical Agreements: Comment", American Economic Review, 77, 1057-1062.

[12] Posner, Richard A. (1976), Antitrust Law: An Economic Perspective, Chicago: University of Chicago Press.

[13] Rasmusen, Eric B., J. Mark Ramseyer and John S. Wiley, Jr. (1991), "Naked Exclusion", American Economic Review, 81, 1137-1145.

[14] Segal, Ilya R. and Michael D. Whinston (2000), "Naked Exclusion: Comment," American Economic Review, 90, 296-309.

[15] Simpson, John and Abraham L. Wickelgren (2001), "The Use of Exclusive Contracts to Deter Entry," Federal Trade Comission, Bureau of Economics Working Papers: No. 241.

[16] Simpson, John and Abraham L. Wickelgren (2007), "Naked Exclusion, Efficient Breach, and Downstream Competition," American Economic Review, 97, 13051320 .

[17] Spier, Kathryn E., and Michael D. Whinston (1995), "On the Efficiency of Privately Stipulated Damages for Breach of Contract: Entry Barriers, Reliance and Renegotiation," RAND Journal of Economics, 26, 180-202.

[18] Stefanidis, Christodoulos (1998), "Selective Contracts, Foreclosure, and the Chicago School View", Journal of Law and Economics, 41, 429-450.

[19] Vives, Xavier (1999), Oligopoly Pricing: Old Ideas and New Tools, Cambridge, MA: MIT Press.

[20] Wright, Julian (2008), "Naked Exclusion and the Anticompetitive Accommodation of Entry", Economics Letters, 98, 107-112.

[21] Wright, Julian (2009), "Exclusive Dealing and Entry, when Buyers Compete: Comment", American Economic Review, 99, 1070-81.

[22] Yong, Jong-Say (1999), "Exclusionary Vertical Contracts and Product Market Competition", Journal of Business, 72, 385-406. 